\title{
Enhancement transient stability of wind power system of Doubly-Fed induction generator using STATCOM and PI controller
}

\author{
Shaimaa Shukri A. Alhalim, Lubna A. Alnabi \\ Departement of Computer Engineering, AL-Mustafa University College, Iraq
}

\begin{tabular}{l} 
Article Info \\
Article history: \\
Received Dec 12, 2018 \\
Revised Apr 19, 2019 \\
Accepted Jul 19, 2019 \\
\hline Keywords: \\
Doubly Feed Induction \\
Generator (DFIG) \\
FACTS device STATCOM \\
MATLAB programming \\
Particle Swarm Optimization \\
(PSO)
\end{tabular}

Article history:

Received Dec 12, 2018

Revised Apr 19, 2019

Accepted Jul 19, 2019 \begin{abstract}
Wind energy is a promising source of electricity in the world and fastest growing. Doubly-Fed Induction Generator (DFIG) systems dominate and widely used in wind power system because of their advantages over other types of generators, such as working at different speeds and not needing continuous maintenance. In this paper used the PI controller and Flexible AC Transmission System (FACTS) device specifically static compensator (STATCOM) to investigate the effect of the controller and FACTS device on the system. PI controller tuning by Particle Swarm Optimization technique (PSO) to limit or reduced the fault current in (DFIG) system. The responses of different kinds of faults have been presented like; two lines to ground faults and three lines to ground faults at different operating conditions. Faults are applied to three proposed controllers; the first controller is the Proportional-Integral (PI), the second controller is PI-controller based on Particle Swarm Optimization (PI-PSO) technique and STATCOM. A reactive power static synchronous compensator (STATCOM) is used, the main aim for the use of STATCOM is to improve the stability of a wind turbine system in addition to this is improving voltages profile, reduce power losses, treatment of power flow in overloaded transmission lines. The simulation programming is implemented using MATLAB program.
\end{abstract}

Copyright (c) 2019 Institute of Advanced Engineering and Science. All rights reserved.

\section{Corresponding Author:}

Shaimaa Shukri A. Alhalim,

Departement of Computer Engineering,

AL-Mustafa University College,

Baghdad-Iraq.

Email: shaimaa.shukri@yahoo.com.

\section{INTRODUCTION}

In recent years, the demand for energy increased as a result of the expansion of the population and to reduce pollution, preserving the environment from conventional fuels. So the need arises to find alternative sources of energy, which ought to be characterized by several features, the most important features that it is friendly to the environment and unending. Among the various sources of renewable energy, Wind power is one of the most promising and fastest growing sources. The growth of technology concerning of wind systems industry produced the development of two types of a wind turbine a fixed speed and variable speed, each one has many advantages and disadvantages according to the use status $[1,2]$. Any system could effect by disturbance such as faults which could be permanent or temporary for this reason fault detection and limit it one of the basic objects in any system. At any instrument that is connected in series or parallel with the load and capable of supplying reactive power demanded by the load is called the reactive power compensation device. Reactive power is the component of power that oscillates back and forth through the lines, being exchanged between electric and magnetic fields [3]. In this paper, proposed a variable speed wind generation system based on (DFIG) with introduces the operation and control of a system. This paper 
describes the effect of PI and STATCOM to overcome on the challenges connected (DFIG) wind turbines the Iraqi national grid and improve the power quality.

The performance of wind turbine (DFIG) with various types of faults is tested and the proposed work is implemented within various technologies design tool MATLAB/Simulink.

\section{MATHEMATICAL MODEL OF DFIG}

Simple analysis and control can be done for three phase electrical machines by using Park transformation. The dynamic equations abc frame should be transformed into rotating dq frame [4-7]. The equations of stator and rotor voltages are:

$$
\begin{aligned}
& V_{d s}=R_{s} i_{d s}-\omega_{s} \Psi_{q s}+\frac{d \Psi_{d s}}{d t} \\
& V_{q s}=R_{s} i_{q s}+\omega_{s} \Psi_{d s}+\frac{d \Psi_{q s}}{d t} \\
& V_{d r}=R_{r} i_{d r}-S \omega_{s} \Psi_{q r}+\frac{d \Psi_{q r}}{d t} \\
& V_{q r}=R_{r} i_{q r}+S \omega_{s} \Psi_{d r}+\frac{d \Psi_{d r}}{d t}
\end{aligned}
$$

and the equations of flux linkage are:

$$
\begin{aligned}
& \Psi_{d r}=L_{r} i_{d r}+L_{m} i_{d s} \\
& \Psi_{q r}=L_{r} i_{q r}+L_{m} i_{q s} \\
& \Psi_{d s}=L_{s} i_{d s}+L_{m} i_{d r} \\
& \Psi_{q s}=L_{s}-i_{q s}+L_{m} i_{q r}
\end{aligned}
$$

The reactive and active powers at rotor and stator side:

$$
\begin{aligned}
& Q_{r}=V_{q r} i_{d r}-V_{d r} i_{q r} \\
& P_{r}=V_{d r} i_{d r}+V_{q r} i_{q r} \\
& Q_{s}=V_{q s} i_{d s}-V_{d s} i_{q s} \\
& P_{s}=V_{d s} i_{d s}+V_{q s} i_{q s}
\end{aligned}
$$

The total output power:

$$
\begin{aligned}
& P_{t}=P_{r}+P_{s}=V_{d r} i_{d r}+V_{q r} i_{q r}+V_{d s} i_{d s}+V_{q s} i_{q s} \\
& Q_{t}=Q_{r}+Q_{s}=V_{q r} i_{d r}-V_{d r} i_{q r}+V_{q s} i_{d s}-V_{d s} i_{q s}
\end{aligned}
$$

The electromagnetic,mechanical torques are:

$$
\begin{aligned}
& T_{e}=\frac{3}{2} \frac{p}{2}\left(\Psi_{d s} i_{q s}-\Psi_{q s} i_{d s}\right) \\
& T_{m}=T_{e}+\frac{J}{p} \frac{d \omega_{r}}{d t}
\end{aligned}
$$

In (1-16) $L_{s}, L_{r}, R_{s}, R_{r}$ represent stator, the rotor winding inductances and resistances and, $L_{m}$ is the mutual inductance. $V_{d r}, V_{q r}, V_{d s}, V_{q s}$ represent direct and quadrate rotor and stator voltages. $i_{d r}, i_{q r}, i_{d s}, i_{q s}$ represent direct and quadrate rotor and stator currents. $\omega_{s}$ the angular velocity of stator current, $S$ slip which equals to $\frac{\omega_{s}-\omega_{r}}{\omega_{S}}, \omega_{r}$ the angular velocity of rotor current. 


\section{WIND FARM MODEL DESCRIPTION}

As a case, the study of the wind farm with 9MW used which contains six 1.5 MW generators connected to a system has voltages and frequency similar to Iraqi National Network as shown in Figure 1. A Doubly-Fed Induction Generator (DFIG) is utilized in this wind farm and an AC/DC/AC IGBT-based PWM converter (Figure 2). The stator of DFIG is connected directly to the $50 \mathrm{~Hz}$ grid and the rotor through converter at a variable frequency.

The DFIG needs two controllers; rotor and grid controller. The main objectives of the rotor controller are; reactive power regulation and stator voltage controlling. The rotor speed regulation is to get a stable operation and changing the set point of speed for capturing maximum wind power. The grid controller is used to keep regulation of the DC-voltage bus and for grid reactive power control.

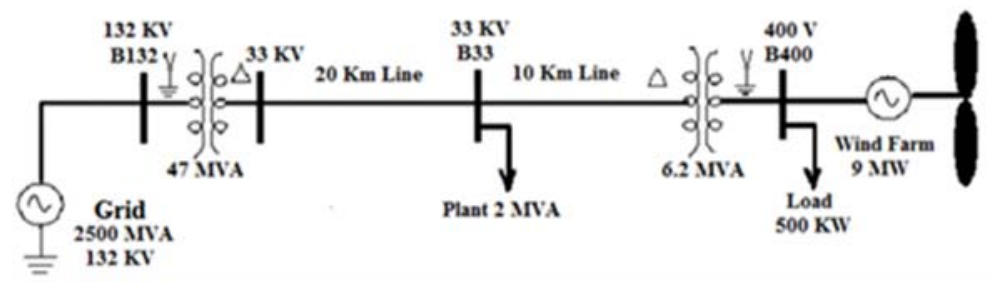

Figure 1. Single line diagram of wind farm connected to grid

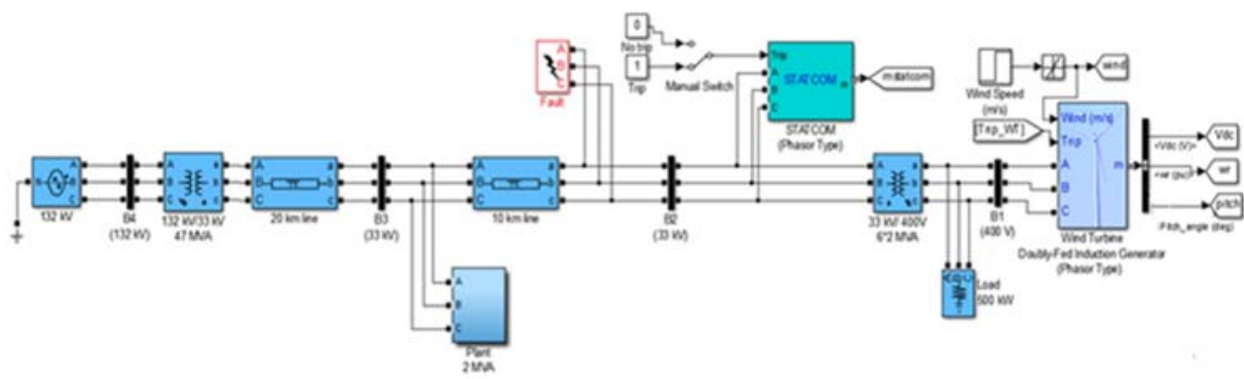

Figure 2. Doubly Fed Induction model

\section{STATCOM MODEL}

A static synchronous compensator (STATCOM) is a shunt connected FACTS device and is generally used to control the magnitude of bus voltage. The power flow through some lines can as well be regulated by controlling the bus voltage magnitude [8]. The STATCOM consists of one VSC and its related shunt transformer. It is the static compensator of the rotating synchronous condenser, but it absorbs or generates reactive power at a faster rate where no moving parts are included. It regulates the voltage at its terminal by changing the quantity of reactive power out or in from the power system. The STATCOM inject reactive power when the system voltage is low and absorbs reactive power when the system voltage is high [9]. The Statcom configuration is shown in Figure 3.

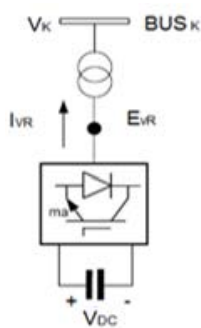

Figure 3. Statcom configuration 


\section{PROPORTIONAL INTEGRAL (PI) CONTROLLER}

It is a feedback mechanism used widely in a variety of applications for many years, it is the optimum choice and will simply outperform almost any other control option. An "error" calculated by the controller, that is the difference between a desired set-point value and the measured process variable. The error minimized by adjusting the inputs. Though this is a powerful instrument, the controllers have to be correctly tuned if they are to be effective. Good control parameters P (Proportional) and I (Integral) can produce a good step response including the overshoot settling time, rise time, and steady-state error [10], [11]. There are four PI controllers used for voltage, current and power control due to their structural simplicity and the ability for applying a wide range of situations as shown in Figures 4-7. Trial and error method are one of the tuning methods which is used in this paper for PI controller gains tuning

\section{PARTICAL SWARM OPTIMIZATION (PSO)}

Russell Eberhart and James Kennedy designed Particle Swarm Optimization (PSO) in 1995. It is a random search algorithm which simulates natured evolutionary processes and is used for solving some difficult optimization problems to perform good characteristics. The basic concept of (PSO) is based on the large numbers of birds when randomly fly and together looking for food. Any bird is called a particle and it's an individual. As a bird looking for foods, the particles are flying in multidimensional search spaces to find optimal solutions. Every particle is composed of family and individual is not isolated from each other.

They remember and share their own flying experience. PSO is very suitable for making the values of parameters at its optimum values. Since it has few parameters for adjusting an optimal solution or for example optimal solution is found with very fast speed convergence, while the PSO process simulates social behaviors of a particle when it moves in multidimensional search spaces. The particles have their positions and velocities. Any particle is a solution for optimization problem which compares its current positions and goal at each time step and its velocity is adjusted towards the goal accordingly with memory to find the best position for each individual and family $[12,13]$. For providing perfect PI tuning PSO techniques are used to get optimal tuning gains of the PI controller. The PSO method depends on Integral. Time Square Error (ITSE) in this work. The implementation of ITSE is done by using an integrator, clock, and product, to obtain square value of error. Error signals are taken which represent the controller inputs (the difference between the reference and actual values), then amplified, squared and integrated. After that, the results should be sent to the PSO MATLAB programming file.

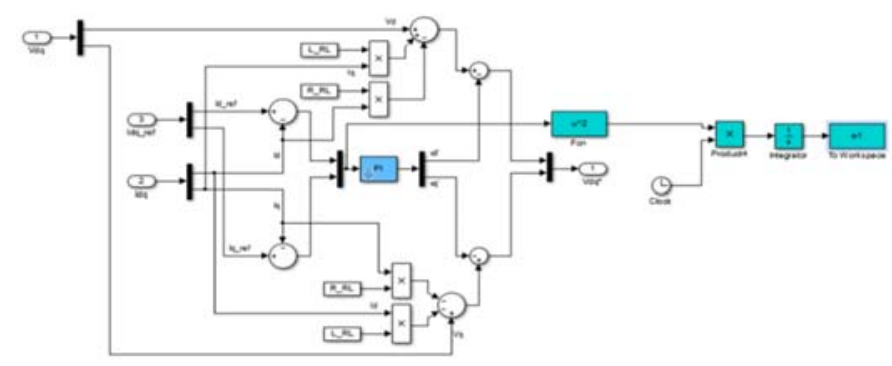

Figure 4. Grid side convertor current control system

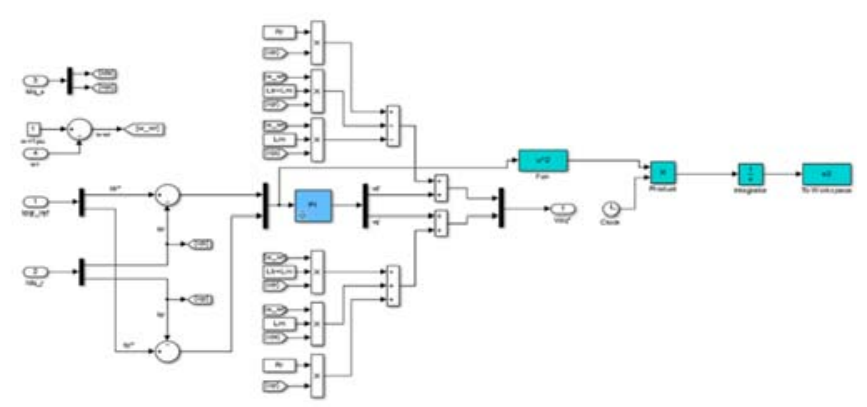

Figure 5. Rotor side convertor current control system

Int J Pow Elec \& Dri Syst Vol. 10, No. 4, Dec 2019 : 1977 - 1985 


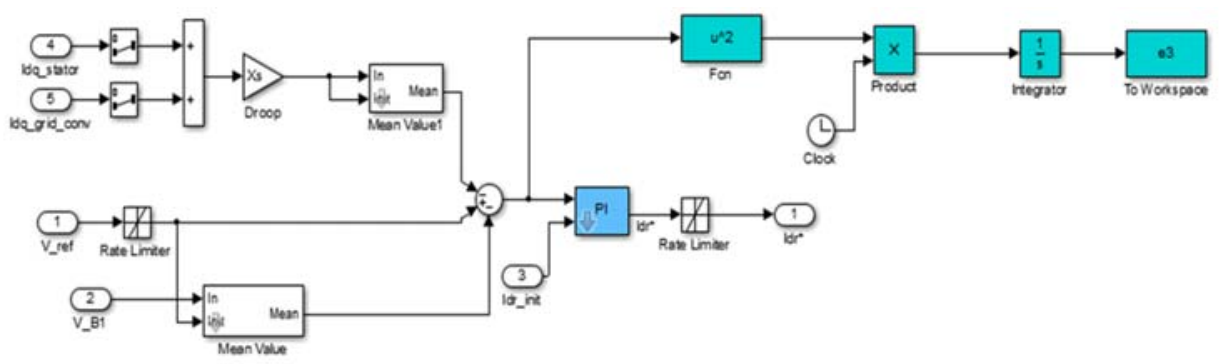

Figure 6. Rotor side convertor voltage control system

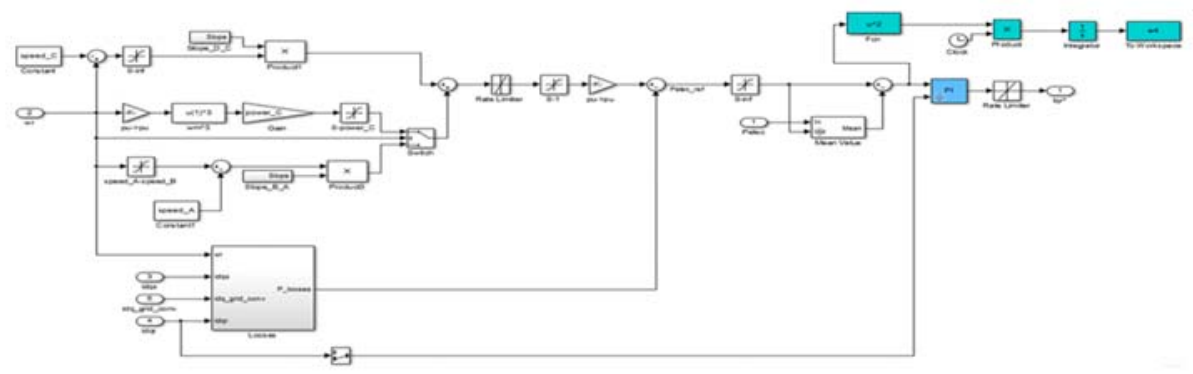

Figure 7. Rotor side converter power control system

\section{SIMULATION RESULTS OF DFIG}

\subsection{Effect of PI Controller Based on PSO}

The simulation of DFIG with PI controller based on PSO is done with applying different types of faults at bus 2 (B2). This technique provides better results where the magnitude of fault current at a high voltage of transformer side is reduced as follows than the trial and error method.

This technique provides better results where the magnitude of fault current at a high voltage of transformer side is reduced as follows than the trial and error method:

\section{Case1: Turbine response to a two line to ground fault}

The system is stable but after a two line to ground fault, in this case, is applied at B2 in Figure 2 and at $\mathrm{t}=35 \mathrm{sec}$ and lasts for $0.1 \mathrm{sec}$. Figures (8) and(9)show the voltage and current are responses, note that the current and voltage in these diagrams illustration are the sum of three currents (Ia, Ib, Ic) and sum of three voltages $(\mathrm{Va}, \mathrm{Vb}, \mathrm{Vc})$.

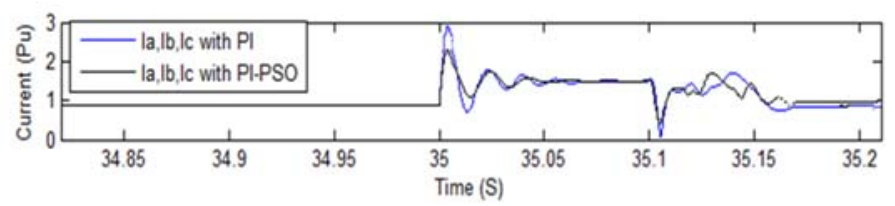

Figure 8. The enlarged scale of three phase current at B2

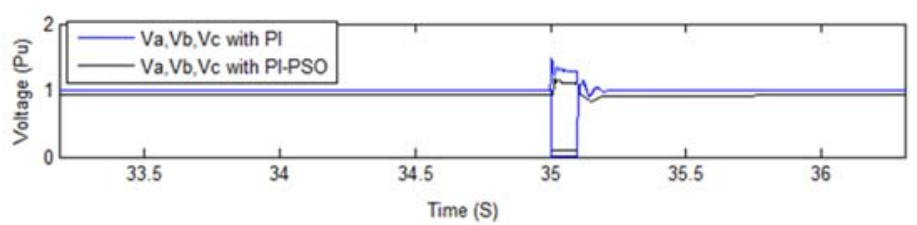

Enhancement transient stability of wind power system of Doubly-Fed ... (Shaimaa Shukri A. Alhalim) 
Figure 9. The enlarged scale of three phase voltage at B2

\section{Case2: Turbine response to a three line to ground fault}

A three line to ground fault, in this case, is applied at B2 in Figure (2) at $t=35 \mathrm{sec}$ and lasts for 0.1 sec. The voltage drops to zero of the three phases with PI controller. This is the most dangerous fault since its magnitude is very high. Figures (10) and (11) show the total voltage and current responses, note that the current and voltage in these diagrams' illustration are the sum of three currents ( $\mathrm{Ia}, \mathrm{Ib}, \mathrm{Ic})$ and sum of three voltages $(\mathrm{Va}, \mathrm{Vb}, \mathrm{Vc})$.

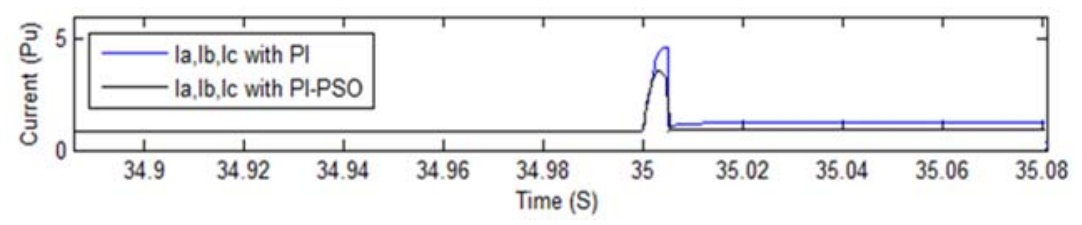

Figure 10. The enlarged scale of three phase current at B2

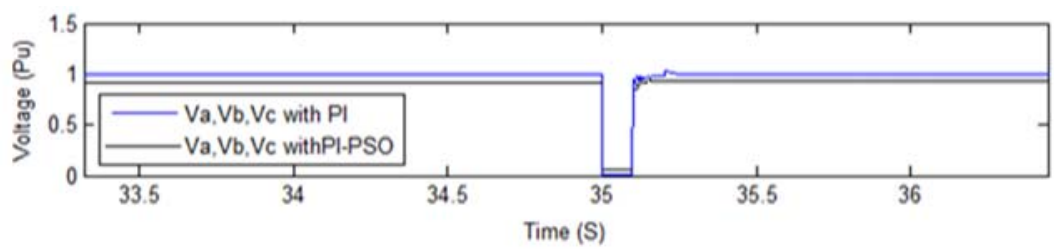

Figure 11. The enlarged scale of three phase voltage at B2

Fault responses can be illustrated as shown in Table (1):

Table 1. Fault responses

\begin{tabular}{|c|c|c|}
\hline Time of the fault (sec) & Start & End \\
\hline \multirow{3}{*}{ Rated value (pu) } & 35 & 35.1 \\
\hline & Phase current & Phase voltage \\
\hline & 0.9 & 1 \\
\hline PI tuned by trial and error & Maximum overshoot of phase current & Minimum overshoot of phase current \\
\hline Two line to ground fault & 3 & 0 \\
\hline Three line to ground fault & 5 & 0 \\
\hline \multicolumn{3}{|c|}{ PI turned based on PSO } \\
\hline Two line to ground fault & 2 & 0.001 \\
\hline Three line to ground fault & 3.9 & 0.001 \\
\hline
\end{tabular}

\subsection{Effect of Statcom}

\section{Case1: Turbine response to a two line to ground fault}

A two line to ground fault, in this case, is applied at B2 in Figure (2) at $\mathrm{t}=35 \mathrm{sec}$ and lasts for 0.1 sec. Figures 12-16 show responses in B2 with and without STATCOM, and who STATCOM work in support of the voltage in B2, note that the current and voltage in these diagrams illustration are the sum of three currents (Ia, Ib, Ic) and sum of three voltages ( $\mathrm{Va}, \mathrm{Vb}, \mathrm{Vc})$.

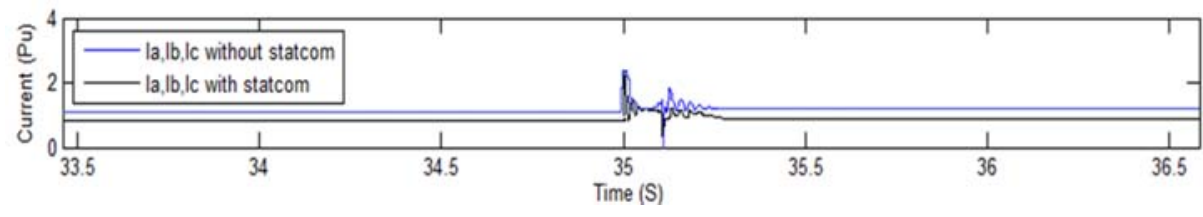

Figure 12. The enlarged scale of three phase current at B2 


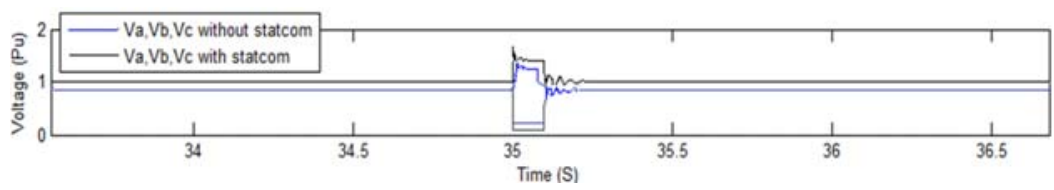

Figure 13. The enlarged scale of three phase voltage at B2

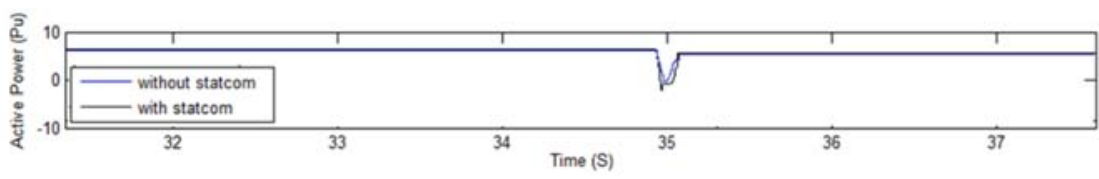

Figure 14. The enlarged scale of active power at B2.

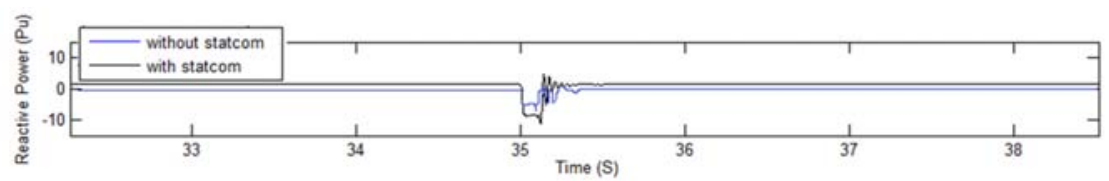

Figure 15. The enlarged scale of reactive power at B2

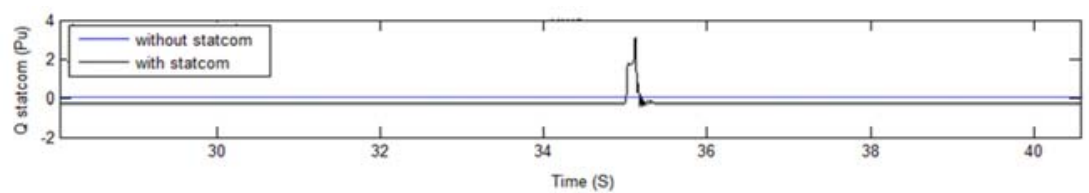

Figure 16. The enlarged scale of injected reactive from STATCOM

\section{Case2: Turbine response to a three line to ground fault}

A three line to ground fault, in this case, is applied at B2 in Figure (2) at $\mathrm{t}=35 \mathrm{sec}$ and lasts for 0.1 sec. Figures 17-21 below show responses in B2 with and without STATCOM, and who STATCOM work in support of the voltage in $\mathrm{B} 2$.

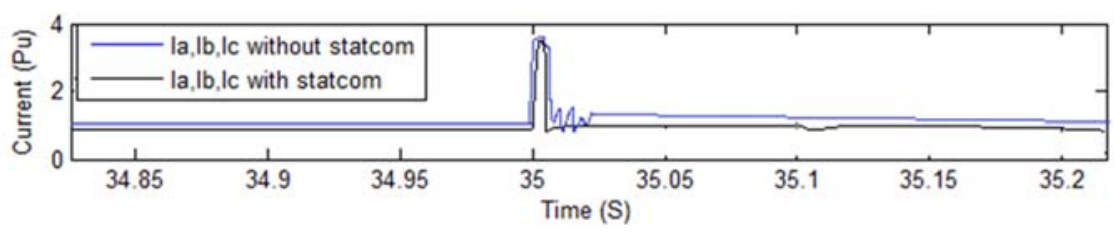

Figure 17. The enlarged scale of three phase current at B2

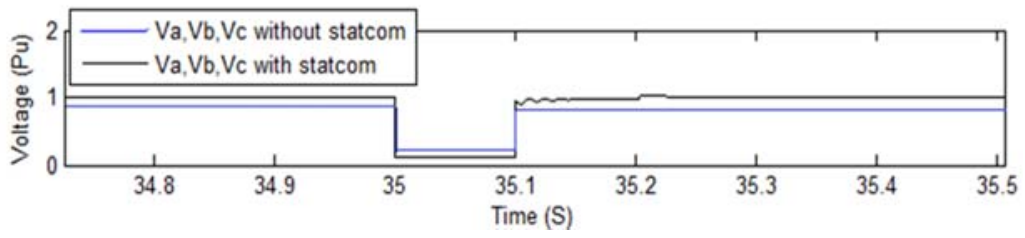

Figure 18. The enlarged scale of three phase voltage at B2 


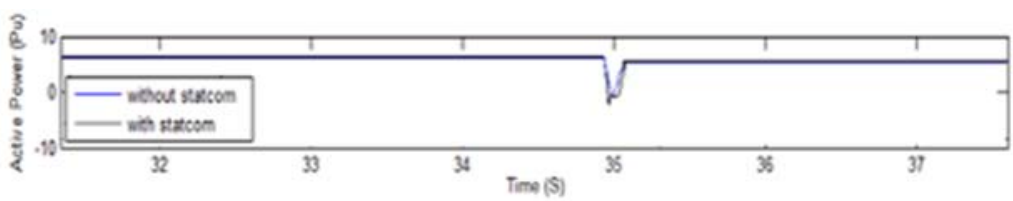

Figure 19. The enlarged scale of active power at B2

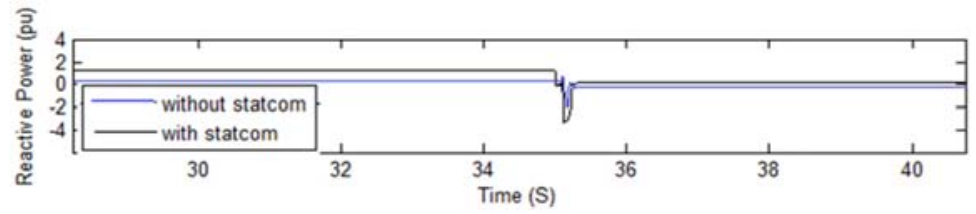

Figure 20. The enlarged scale of reactive at B2

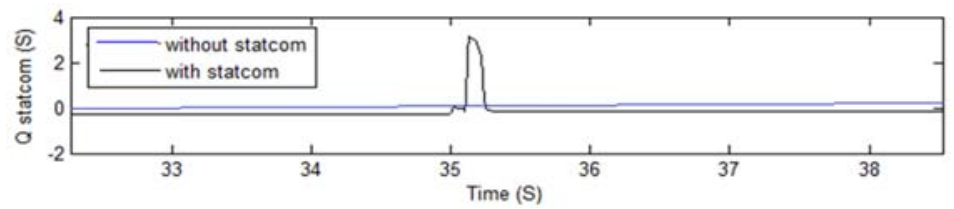

Figure 21. The enlarged scale of injected reactive power from STATCOM

Table 2 illustrates a comparison of the system with and without STATCOM for reactive power, voltage and current at bus 2 .

Table 2. Comparison of system with and without STATCOM

\begin{tabular}{|c|c|c|}
\hline \multicolumn{3}{|c|}{ Rated With STATCOM Without STATCOM } \\
\hline \multicolumn{3}{|c|}{ Case1: At two line to ground fault } \\
\hline \multicolumn{3}{|c|}{$\begin{array}{l}\text { Reactive power } 108 \\
\text { (MVAR) }\end{array}$} \\
\hline \multicolumn{3}{|c|}{ Voltage (pu) 0.010 .001} \\
\hline \multicolumn{3}{|c|}{ Current (pu) 1.942} \\
\hline \multicolumn{3}{|c|}{ Case2: At three phase to ground fault } \\
\hline $\begin{array}{l}\text { Reactive power } \\
\text { (MVAR) }\end{array}$ & 3.5 & 2 \\
\hline Voltage (pu) & 0.01 & 0.001 \\
\hline Current (pu) & 3.84 & 3.9 \\
\hline
\end{tabular}

\section{CONCLUSION}

Different types of faults (symmetrical and unsymmetrical) are applied at a high voltage of transformer at bus 2 (B2) of (DFIG) to investigate the performance of (DFIG). Particle Swarm Optimization (PSO) is used with (PI) controller to choose the optimum magnitude of (PI) gains. Therefore, the fault current magnitude using (PI-PSO) is reduced. Power system with wind farm performance enhanced using one of (FACTS) devices (STATCOM).

The position of (STATCOM ) is improving the system stability leads to improve all the elements of power equality of grid for both abnormal and normal condition, then reduce losses in all system due to power factor(PF) improvement by reducing the current drawn and therefore, the proposed use (STATCOM) with a farm wind turbine (DFIG). 


\section{APPENDIX}

Parameters of the DFIG used in the paper. The parameters values of Doubly-Fed Induction Generator (DFIG) used in the simulation are illustrated in Table 3.

Table 3. Parameters of Doubly-Fed Induction Generator (DFIG).

\begin{tabular}{lc}
\hline Rated Output Power $(\mathrm{MW})$ & $9 \mathrm{MW}\left(6^{* 1.5}\right)$ \\
\hline Rated Voltage V(L-L) $(\mathrm{V})$ & $400 \mathrm{~V}$ \\
Frequency $(\mathrm{Hz})$ & $50(\mathrm{~Hz})$ \\
Pairs of poles $(\mathrm{P})$ & 3 \\
Stator winding resistance $\left(R_{S}\right)(\mathrm{pu})$ & 0.00706 \\
Stator leakage inductance $\left(L_{S}\right)(\mathrm{pu})$ & 0.171 \\
Rotor winding resistance $\left(R_{r}\right)(\mathrm{pu})$ & 0.005 \\
Rotor leakage inductance $\left(L_{r}\right)(\mathrm{pu})$ & 0.156 \\
Magnetizing inductance $\left(L_{m}\right)(\mathrm{pu})$ & 2.9 \\
Rated wind speed at point C $(\mathrm{m} / \mathrm{s})$ & 12 \\
Cut-in speed $(\mathrm{m} / \mathrm{s})$ & 4 \\
Cut-out speed $(\mathrm{m} / \mathrm{s})$ & 25 \\
Maximum pitch angle $(\mathrm{deg})$. & 45 \\
Maximum rate of change of pitch angle $(\mathrm{deg} . / \mathrm{s})$ & 2 \\
Inertia constant $\left(\mathrm{Kg} m^{2}\right)$ & 5.04 \\
\hline
\end{tabular}

\section{REFERENCES}

[1] Waheed A. Oyekanmi, Ghadir Radman, "Effect of Static VAR Compensator positioning on a Grid-connected wind turbine-driven Squirrel Cage Induction Generator," IEEE conference publications, pp. 247 - 252 , 2013.

[2] Sreedhar Reddy Guda, "Modeling and Power Management of a Hybrid WindmicroTurbine Power Generation System," Electrical Engineering, Montana State University, Bozeman, Montana, 2005.

[3] M. Packiasudha1, S. Suja2, "FACT Device for Reactive Power Compensation in the Deregulated Electrical Power Environmen," International Journal of Power Electronics and Drive System (IJPEDS), vol. 6(4), pp. 730-735, 2015.

[4] Q. F. Lu, Z. T. Cao and E. Ritchie, "Model of Stator Inter-turn Short Circuit Fault in Doubly-fed Induction Generators for Wind Turbine", IEEE Conference Publications, Vol. 2, pp. 932-937 2004.

[5] Vincenz Dinkhauser and Friedrich W. Fuchs, "Rotor Turn-to-Turn Faults of Doubly-Fed Induction Generators in Wind Energy Plants-Modelling, Simulation and Detection," IEEE Conference Publications, no. 17, pp. 1819-1826, 2008.

[6] Shahram Karimi, Arnaud Gaillard, Philippe Poure and Shahrokh Saadate, "FPGA-Based Real-Time Power Converter Failure Diagnosis for Wind Energy Conversion Systems," IEEE Transactions Industrial Electronics, vol. 55(12), pp. 4299-4308, 2008.

[7] Olumide Aluko, Travis M. Smith and Leon M. Tolbert, "Behavior of Doubly-Fed Induction Generator under Nearby Wind Plant Fault," IEEE Conference Publications, Power and Energy Society General Meeting, (4), pp. $1-5,2010$.

[8] M.H. Haque, "Use of Series and Shunt FACTS Devices to Improve First Swing Stability Limit," IEEE, 2011

[9] M. M. Fard et al., "UPFC Using for The Congestion Management Lines in Electricity Market Restructured Using PSO and GA Algorithm," Restructured Using PSO and GA Algorithm, vol. 5(10), 2011.

[10] Jinghua Zhong, "PID Controller Tuning a Short Tutorial," Mechanical Engineering, Purdue University, 2006.

[11] Guillermo J. Costa, "Tuninga PID Controller," power transmission engineering, 2011. www.powertransmission.com .

[12] Yaser M. Abid, "Design of Intelligent Controller for Solar Tracking System Based on FPGA," M.Sc. Thesis, University of Technology, Electrical Engineering Department, 2014.

[13] Ling Wang, "A Novel Probability Binary Particle Swarm Optimization Algorithm and its Application," Journal of Software, vol. 3(9), pp. 28-35, 2008. 